\title{
Multiplex CRISPR/Cas9 Mutagenesis of BrVRN1 Delays Flowering Time in Chinese Cabbage (Brassica rapa $\mathrm{L}$. ssp. pekinensis)
}

\author{
Joon Ki Hong, Eun Jung Suh, Sang Ryeol Park (1), Jihee Park and Yeon-Hee Lee * \\ Agricultural Biotechnology Department, National Institute of Agricultural Sciences, Rural Development \\ Administration, 370 Nongsaengmyeong-ro, Jeonju 54874, Korea; jkhongok@korea.kr (J.K.H.); \\ seji00@korea.kr (E.J.S.); srpark@korea.kr (S.R.P.); heeya91@korea.kr (J.P.) \\ * Correspondence: yhl2222@korea.kr; Tel.: +82-63-238-4690
}

Citation: Hong, J.K.; Suh, E.J.; Park, S.R.; Park, J.; Lee, Y.-H. Multiplex CRISPR/Cas9 Mutagenesis of BrVRN1 Delays Flowering Time in Chinese Cabbage (Brassica rapa L. ssp. pekinensis). Agriculture 2021, 11, 1286. https://doi.org/10.3390/

agriculture11121286

Academic Editor: Rodomiro Ortiz

Received: 11 November 2021

Accepted: 13 December 2021

Published: 17 December 2021

Publisher's Note: MDPI stays neutral with regard to jurisdictional claims in published maps and institutional affiliations.

Copyright: (c) 2021 by the authors. Licensee MDPI, Basel, Switzerland. This article is an open access article distributed under the terms and conditions of the Creative Commons Attribution (CC BY) license (https:// creativecommons.org/licenses/by/ $4.0 /)$.
Abstract: The VERNALIZATION1 (VRN1) gene is a crucial transcriptional repressor involved in triggering the transition to flowering in response to prolonged cold. To develop Chinese cabbage (Brassica rapa L. ssp. pekinensis) plants with delayed flowering time, we designed a multiplex CRISPR/Cas9 platform that allows the co-expression of four sgRNAs targeting different regions of the endogenous BrVRN1 gene delivered via a single binary vector built using the Golden Gate cloning system. DNA sequencing analysis revealed site-directed mutations at two target sites: gRNA1 and gRNA2. $\mathrm{T}_{1}$ mutant plants with a 1-bp insertion in BrVRN1 exhibited late flowering after the vernalization. Additionally, we identified 'transgene-free' $B r V R N 1$ mutant plants without any transgenic elements from the $\mathrm{GE}_{1}$ (gene-editing 1 ) and $\mathrm{GE}_{2}$ generations. All $\mathrm{GE}_{2}$ mutant plants contained successful edits in two out of three $\mathrm{BrVRN1}$ orthologs and displayed delayed flowering time. In $\mathrm{GE}_{2}$ mutant plants, the floral repressor gene $F L C 1$ was expressed during vernalization; but the floral integrator gene $F T$ was not expressed after vernalization. Taken together, our data indicate that the $B r V R N 1$ genes act as negative regulators of $F L C 1$ expression during vernalization in Chinese cabbage, raising the possibility that the 'transgene-free' mutants of BrVRN1 developed in this study may serve as useful genetic resources for crop improvement with respect to flowering time regulation.

Keywords: Brassica rapa; BrVRN1; CRISPR/Cas9; late flowering; transgene-free; vernalization

\section{Introduction}

Chinese cabbage (Brassica rapa L. ssp. pekinensis) is an important vegetable crop that contributes to human health as a source of beneficial dietary fiber, vitamins, and minerals [1]. Because it is responsive to seed vernalization, Chinese cabbage is prone to premature bolting, which affects crop yield and quality. This is particularly true in spring varieties that are often exposed to extended periods of cold during winter [2-4].

A properly timed transition from vegetative to reproductive development is the most important step in the life cycle of a flowering plant. Flowering time plasticity has evolved to integrate plants' perceptions of both seasonal and developmental changes to maximize reproductive success in various environments. Flowering time has also emerged as a key trait affecting yield in commercial agronomic and horticultural crops because certain biotic and abiotic stresses can be avoided altogether by inducing or delaying the transition to flowering. Multiple pathways, such as photoperiod sensation, vernalization, gibberellin signaling, and responses to autonomous signals, are involved in the timing of floral transition during specific seasons, and altered flowering time phenotypes have been generated in multiple cultivated species through targeted genetic modification [5-9]. Vernalization, the induction of flowering by prolonged cold, ensures that plants flower in favorable spring conditions, and is usually required for flowering in Brassicaceae. Because 
Chinese cabbage can sense low temperatures during seed germination, it sometimes undergoes early flowering (bolting) due to low temperatures in the fall $[10,11]$. Premature bolting leads to a decline in commercial quality and a loss of market value, so a high bolting resistance is preferred when breeding cultivars of this species [10].

To facilitate these breeding efforts, extensive genetic analysis in Arabidopsis thaliana has identified several genes, including FRIGIDA (FRI) and FLOWERING LOCUS C (FLC), that play vital roles in the flowering process. $F R I$ encodes a plant-specific nuclear protein that promotes high expression of FLC [12]. FLC encodes a MADS-box transcription factor that prevents flowering by suppressing the expression of the floral integrator genes FLOWERING LOCUS T (FT) and SUPPRESSOR OF OVEREXPRESSION OF CONSTANS 1 (SOC1) [13-16]. The FLC expression level negatively correlates with flowering time after vernalization, and is suppressed by exposure to a long period of cold temperatures [17]. The duration of vernalization, therefore, represses FLC expression in order to promote flowering in vernalization-responsive late-flowering plants. Thus, FLC is thought to be a major determinant of the vernalization response. In Arabidopsis, FLC expression is decreased through a vernalization mechanism involving VERNALIZATION INSENSITIVE 3 (VIN3), and this repression is epigenetically maintained by a Polycomb-like chromatin regulation involving VERNALIZATION 2 (VRN2), a Su(z)12 homolog, VERNALIZATION 1 (VRN1), and LIKE-HETEROCHROMATIN PROTEIN 1 [18-23].

$V R N 1$ encodes a DNA-binding protein containing two plant-specific B3 domains that is required for stable repression of the major target of the vernalization pathway, the floral repressor $F L C$, during prolonged cold treatment [23,24]. In Arabidopsis, expression levels of AtVRN1 and AtVRN2 are not affected by vernalization [22,23]. However, vrn1-2 mutant plants grown in extended short-day (ESD) conditions showed reduced FT but wild-type FLC expression, suggesting that VRN1 regulates FLC and FT [23]. In Chinese cabbage, the expression of $B r V R N 1$ genes is altered by cold treatment, according to patterns that vary among the three paralogous genes: two BrVRN1 genes are downregulated during cold treatment, and one is upregulated. It is therefore possible that the suppression of BrFLC expression is dependent on the upregulation of $B r V R N 1$ by vernalization in B. rapa [25].

Despite genetic analysis of floral transition regulation in Arabidopsis and the identification of floral regulator genes in Chinese cabbage, there have been few reports on the mechanism of floral transition in Chinese cabbage specifically [26,27]. Recently, several studies have set out to directly control flowering time via CRISPR/Cas9-mediated genome editing [28,29]. In this study, we used the CRISPR/Cas9 system for targeted mutagenesis of BrVRN1 homologs (BrVRN1s) to introduce the late-flowering trait into B. rapa [25]. CRISPR/Cas9-mediated multi-target mutagenesis of BrVRN1s gave new insights into flowering time regulation and demonstrated that genome editing can be used to improve agricultural traits in B. rapa.

\section{Material and Methods}

\section{1. sgRNA Target Site Design and Vector Construction}

sgRNAs were designed using the web tool Cas-Designer (http://www.rgenome. net/cas-designer/, accessed on 8 July 2019) [30], which displayed all optional sgRNA sequences (20 bp) immediately followed by a $5^{\prime}$-NGG protospacer-adjacent motif (PAM) sequence in the forward or reverse strand. Sequences of the Chinese cabbage VRN1 genes (BrVRN1a, Bra022375, BrVRN1b, Bra037544, and BrVRN1c, Bra001729) were compared to find a region with matching sequences (Figures $1 \mathrm{a}$ and S1 and Table S1). Then, four sgRNAs were designed in the corresponding region to target the BrVRN1a (Bra022375) gene [25]. To construct a plasmid vector carrying four sgRNAs and the Cas9 cassette, we designed a multiplex CRISPR/Cas9 platform that allows the co-expression of four sgRNA modules targeting different sites of BrVRN1 in one binary vector (pAGM4723) using Golden Gate assembly (Figure 1b) [31]. The sequence of Cas9 was assembled downstream of the Cauliflower mosaic virus (CaMV) $2 \times 35$ S promoter along with four custom sgRNAs driven by four Arabidopsis U6-26 promoters. The hygromycin-resistance gene (hpt) driven by 
a nos promoter was used as a selectable marker. The final vector was introduced into Agrobacterium tumefaciens GV3101 and then used for the transformation of Chinese cabbage.

a

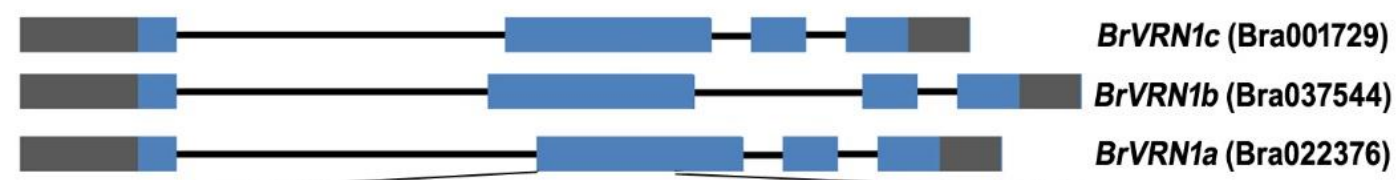

TTTCAAGGACGAGCTATCCGTAGCAGTTGCACTCACAGTACCTGATGGTCACGTTTGGCGTGTAGGACTAAGAAAATCOG AAAGTTCCTGCTCGATAGGCATCGTCAACGTGAGTGTCATGGACTACCAGTGCAAACCGCACATCCTGATTCTTTTAGGC PAM gRNA1 gRNA2 PAM

ACAACAACAAAATCTACTTTCAAGATGGTTGGCAAGAGTTTGTCGACCGTTACTCAATCCGCATTGGCTATCTTCTCATC TGTTGTTGTTTTAGATGAAAGTTCTACCAACCGTTCTCAAACAGCTGGCAATGAGTTAGGCGTAACCGATAGAAGAGTAG

TTCAGATACGAAGGCAACTCTGCCTTCAGTGTCTACATTTACAACTTATCACACTCCGAGATCAACTACCATTCCTCCGC AAGTCTATGCTTCCGTTGAGACGGAAGTCACAGATGTAAATGTTGAATAGTGTGAGGCTCTAGTTGATGGTAAGGAGGCG

TCTCATGGACACCGCACACACCCACCTCAAACGCGCCCGTTTGTTTGAAGATCTTGAAGACGAAGACGCCGCCGAGGTTG AGAGTACCTGTGGCGTGTGTGGGTGGAGTTTGCGCGGGCAAACAAACTTCTAGAACTTCTGCTTCTGCGGCGGCTCCAAC PAM

TTTATCCTTCTTCTTCAGTGTATCCGTCATCACAACAGCATCCTGAAGTTACTGTGGCOGCTATTAAAGGGTACGCTAGT AAATAGGAAGAAGAAGTCACATAGGCAGTAGTGTTGTCGTAGGACTTCAATGACACCGGCGATAATTTCCCATGCGATCA gRNA3 PAM gRNA4

b

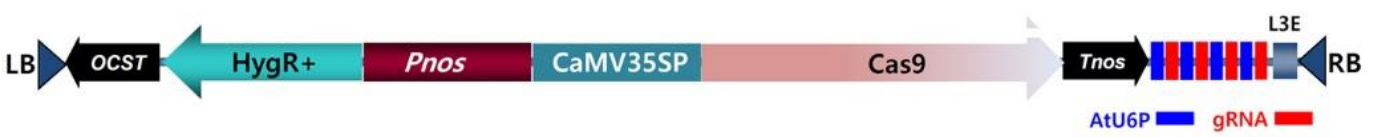

Figure 1. Multiplex gene editing construction of BrVRN1 family gene. (a) Gene structure of BrVRN1a with target sites of CRISPR/Cas9 designed in the second exon. Blue stripe, exon; black line, intron; grey stripe, UTR (untranslated regions). The underlined nucleotides indicate the target sites (named gRNA1 to gRNA4). Nucleotides in red represent PAM sequences. PAM, protospacer adjacent motif. (b) Structure of CRISPR/Cas9 platform with BrVRN1a four sgRNAs vector based on pAGM4723. AtU6P, Arabidopsis U6 promoter; Pnos, nopaline synthase promoter; Tnos, nopaline synthase terminator; LB, left border; RB, right border; HygR+, hygromycin-resistance gene; OCST, octopine synthase terminator; L3E, end linker 3; CaMV35P, 35S promoter.

\subsection{Generation of Transgenic Chinese Cabbage Plants}

The late-flowering Chinese cabbage cultivar 'inbred line DA001' was used for transformation according to previously published methods with minor modifications [32,33]. Surface-sterilized seeds were placed on Murashige and Skoog (MS) medium (MS basal medium, $3 \%$ sucrose, and $0.8 \%$ Phytagar) and germinated in a culture room under long-day conditions ( $16 \mathrm{~h}$ light $/ 8 \mathrm{~h}$ dark) at $25^{\circ} \mathrm{C}$ for 7 days. Hypocotyls were cut into $0.5 \mathrm{~cm}$ segments and placed on pre-culture medium (MS basal medium, $1 \mathrm{mg} / \mathrm{L} \mathrm{NAA}, 3 \mathrm{mg} / \mathrm{L} \mathrm{BA}$, $2 \mathrm{mg} / \mathrm{L} \mathrm{AgNO} 3,3 \%$ sucrose, and $0.8 \%$ Phytagar) for 2 days. The pre-cultured hypocotyls were inoculated with Agrobacterium suspension $\left(\mathrm{OD}_{600}=0.3\right)$ in MS liquid medium for 15-20 min with gentle shaking. The inoculated hypocotyls were blotted with sterilized filter paper to remove excess bacterial suspension and co-cultivated on co-cultivation medium (MS basal medium, $1 \mathrm{mg} / \mathrm{L}$ NAA, $3 \mathrm{mg} / \mathrm{L}$ BA, $2 \mathrm{mg} / \mathrm{L} \mathrm{AgNO}_{3}, 100 \mu \mathrm{M}$ acetosyringone, $3 \%$ sucrose, and $0.8 \%$ Phytagar) for 3 days in darkness at $25 \%$. Hypocotyls were then washed with sterilized water containing $100 \mathrm{mg} / \mathrm{L}$ carbenicillin and $250 \mathrm{mg} / \mathrm{L}$ cefotaxime and transferred to selective medium (MS basal medium, $1 \mathrm{mg} / \mathrm{L} \mathrm{NAA}, 3 \mathrm{mg} / \mathrm{L} \mathrm{BA}, 2 \mathrm{mg} / \mathrm{L} \mathrm{AgNO}_{3}$, $3 \%$ sucrose, $100 \mathrm{mg} / \mathrm{L}$ carbenicillin, $250 \mathrm{mg} / \mathrm{L}$ cefotaxime, and $0.8 \%$ Phytagar) supplemented with $10 \mathrm{mg} / \mathrm{L}$ hygromycin as a selective agent. Callus that formed on hypocotyls was sub-cultured on fresh selective medium every 2-3 weeks. Healthy and elongated shoots were excised and transferred to a phytohormone-free MS medium to induce rooting. The transformed plantlets were grown in a greenhouse after acclimatization. 


\subsection{Confirmation of the Mutations of Transgenic Plants}

To confirm the stable integration of transgenes in Chinese cabbage, the dual-genomic DNA-PCR was performed. Genomic DNA PCR was carried out using a pair of $h p t$-specific primers (forward, $5^{\prime}$-AGCCTGAACTCACCGCGACGTCTGTCGAGAAGTTTC-3' ; reverse, 5'-TCTACACAGCCATCGGTCCAGACGGCCGCGCTTCTG-3'; 961 bp PCR product) and two pairs of Cas9-specific primers (SP1-forward, $5^{\prime}$-TCCTCCCGAAAAGGAACAGCGAC3'; SP1-reverse, 5'-CATTCGTTTCCGGCCGTTTTCAAG-3'; 311 bp PCR product, SP2forward, 5'-CAACTGGTTCAGACTTACAATCAGC-3'; ; SP2-reverse, 5' -TTCCAAGATGGG CTTAATAAATTTG-3'; 1031 bp PCR product). The PCR reactions were performed using 35 cycles of $30 \mathrm{~s}$ at $95{ }^{\circ} \mathrm{C}, 30 \mathrm{~s}$ at $55^{\circ} \mathrm{C}$, and $40 \mathrm{~s}$ at $72{ }^{\circ} \mathrm{C}$, followed by a final extension at $72{ }^{\circ} \mathrm{C}$ for $10 \mathrm{~min}$. The resulting PCR products were analyzed using electrophoresis and ethidium bromide staining.

To verify BrVRN1 mutations in gene-edited plants, genomic DNA was isolated from transgenic leaf samples using the CTAB method, and then PCR, Sanger sequencing, and deep sequencing were performed. To confirm BrVRN1 mutations in $\mathrm{T}_{0}$ and $\mathrm{T}_{1}$ generation plants, as well as in gene-edited plants without transgenes ( $\mathrm{GE}_{1}$ plants, sequences adjacent to the four sgRNA target positions were amplified with primer sets (target1 and target2, 5' -AGGACGAGCTATCCGTAGCA-3' ' 5' -GGCAGAGTTGCCTTCGTATC-3'; target 3 and target $4,5^{\prime}$-TACCATTCCTCCGCTCTCAT- $3^{\prime}, 5^{\prime}$-TAGGAGTTGGTGTCGCCTCT$3^{\prime}$ ). PCR products were subjected to deep sequencing performed at ToolGen Inc. (ToolGen, Seoul, Korea) to detect mutations [34]. Also, to verify the mutations in the three $B r V R N 1$ genes in the $\mathrm{GE}_{1}$ and $\mathrm{GE}_{2}$ plants, Sanger sequencing was performed using three gene-specific amplicons generated using intron-specific primer sets (BrVRN1a, $5^{\prime}$ TATACAATGTTCCAGGAATAGTAATGGAC- $3^{\prime}, 5^{\prime}$-ACCAATCATCACAATCAATCCAAG AATG-3'; BrVRN1b , 5'-GAACCATTTGGATTGTGATTTTAAATTAA-3' 5 $^{\prime}$-AATTTTCGGTT CAGTTCAGCCGGTTTGG-3'; BrVRN1c, 5'-CCTAAAGGTTACAAGCA0GTCTCATTTAT$3^{\prime}, 5^{\prime}$-TCACTACTAAACAATAGTCTGAAGAATC-3'). PCR amplicons from $\mathrm{GE}_{1}$ and $\mathrm{GE}_{2}$ plants were cloned into the pGEM-T vector (Promega, Madison, WI, USA), and 100 plasmids were Sanger-sequenced. For verification of on- and off-target editing events, as well as homozygosity, in the $\mathrm{GE}_{2}$ generation, $\mathrm{SNP}$ and insertion/deletion (indel) analyses were performed using next-generation sequencing (NGS) at SEEDERS Inc. (SEEDERS, Daejeon, Korea). Raw sequencing reads of individual paralogs were used as queries, which were then compared to the provided non-edited reference genome sequence (Table S2) [35-40].

\subsection{RNA Extraction and Real-Time Reverse Transcription Quantitative PCR (qPCR) Analysis}

To analyze the expression of floral-related genes in transgenic plants, qPCR was performed using primer sets specific to flowering genes (BrFLC1, 5'-GTGCGGCTGCTTGAACA T-3' ${ }^{\prime} 5^{\prime}$-CCTGACCAGGCTGGAGAAA- $3^{\prime} ;$ BrFT, $5^{\prime}$-ACTTTGGTTATGGTGGATCCAGATG T- $3^{\prime}$, and $5^{\prime}$-GGAAGGCCGAGATTGTATAGGGAA-3') [41,42]. Samples were collected from the leaf tissue of $\mathrm{GE}_{2}$ plants at different growth stages. Total RNA was extracted from $100 \mathrm{mg}$ of leaf tissue using the RNeasy Plant Mini Kit (Qiagen, Hilden, Germany) and treated with DNase I (New England Biolabs, Ipswich, MA, USA) to remove genomic DNA. First-strand cDNA was synthesized from $2 \mu \mathrm{g}$ of total RNA using MMLV reverse transcriptase (RNaseH-free; Toyobo, Osaka, Japan) according to the manufacturer's instructions. The cDNA was resuspended in nuclease-free water (Promega, Madison, WI, USA) and used for qPCR analysis with a CFX Connect ${ }^{\mathrm{TM}}$ Real-Time PCR Detection System (Bio-Rad, Hercules, CA, USA). BrActin was used as an internal control for normalizing mRNA levels [41,42]. Three biological replicates were analyzed for each qRT-PCR assay, and Student's $t$-test was used for statistical analyses.

\subsection{Flowering Time Analysis}

Transgenic Chinese cabbage plants with $4-5$ leaves were transferred to a $4{ }^{\circ} \mathrm{C}$ growth chamber (for vernalization) under long-day conditions ( $16 \mathrm{~h}$ light $/ 8 \mathrm{~h}$ dark) for 40-60 days. After vernalization, plants were transplanted into $25 \mathrm{~cm}$ diameter pots and transferred to 
a greenhouse to observe flowering time phenotypes in March and September [32]. The flowering time of $\mathrm{GE}_{1}$ and $\mathrm{GE}_{2}$ plants was recorded as the number of days until the appearance of a bolt with a floral bud. Progeny seeds were obtained using bud-pollination.

\section{Results}

\subsection{Identification and CRISPR-Cas9 Mutagenesis of BrVRN1 Genes}

To identify orthologs of the AtVRN1 gene in Chinese cabbage, we used an AtVRN1 (At3g18990) sequence for a BLAST query in the B. rapa database (BRAD, http:/ / brassicadb. org, accessed on 15 March 2019), which revealed three paralogs (Table S1), which we refer to as $B r V R N 1 a, B r V R N b$, and $B r V R N 1 c$. The sequence similarity between the paralogs ranged between $89.1 \%$ and $90.7 \%$. A previous study showed that under cold treatment, BrVRN1a (Bra022376) is upregulated, while its paralogs BrVRN1b (Bra037544) and BrVRN1c (Bra001729) are downregulated $[25,41]$. We expected that knocking out any one paralog in Chinese cabbage would give comparable phenotypic results and therefore focused on $B r V R N 1 a$. We selected four target sites (gRNA1-gRNA4) in the second exon of BrVRN1a (Figures 1a and S1 and Table S3) and transformed the corresponding multiplex plasmid vector carrying four sgRNAs and a Cas9 cassette into Chinese cabbage (B. rapa L. ssp. pekinensis) via Agrobacterium-mediated transformation (Figure 1b).

Next, we performed hypocotyl transformation to introduce the CRISPR/Cas9 construct into the late-flowering Chinese cabbage cultivar 'inbred line DA001'. The efficiency of callus formation from hypocotyls infected with Agrobacterium on selection medium supplemented with hygromycin was $36 \%$ (data not shown), and we obtained nineteen independent $\mathrm{T}_{0}$ transformants (Table S4). Before transferring the transgenic plants to the soil, we used genomic DNA extracted from $\mathrm{T}_{0}$ leaf tissue to examine the CRISPR/Cas9-induced mutations at the target sites using deep-sequencing analysis (data not shown). We identified mutations in 10 independent $\mathrm{T}_{0}$ lines regenerated into whole plants, demonstrating the efficacy of the selected sgRNAs in Chinese cabbage. Deep-sequencing of these lines revealed an overlay of more than two different sequences (Figure S2), suggesting that these were chimeric plants containing different mutations and that some mutations might have occurred somatically. Among these 10 mutants, we were able to harvest seeds from three lines (\#1, \#2, and \#7), which we planted under vernalization conditions in Jeonju, Korea, and used for further studies.

\subsection{Generation of 'Transgene-Free' Mutant Lines}

We expected that chimeric $\mathrm{T}_{0}$ plants would give rise to complex segregation patterns in the $\mathrm{T}_{1}$ generation and that homozygous mutants could only be selected from later generations. We tested thirty-seven $\mathrm{T}_{1}$ plants (19 from line \#1, 13 from line \#2, and 5 from line \#7) for the presence of transgenes. Also, to obtain BrVRN1a mutants without any transgenic elements of the sgRNAs/Cas9 vector, we screened 'transgene-free' plants through a dual-PCR strategy that used two sets of primers flanking the Cas9 and hph (hygromycin B phosphotransferase) genes (Figure S3). This showed that two (\#2-2 and $\# 2-8$ ) of the $13 \# 2 T_{1}$ mutants were 'transgene-free', and their 20 offspring plants were all 'transgene-free' BrVRN1 mutants (Figure S4). We then conducted deep-sequencing of two selected 'transgene-free' $\mathrm{GE}_{1}$ (gene-editing 1) lines, which confirmed BrVRN1 gene editing based on the proportion of indels. The 1-bp insertion type was most frequently identified in the BrVRN1-gRNA1 and BrVRN1-gRNA2 target regions but was not found in the BrVRN1-gRNA3 and BrVRN1-gRNA4 target regions (Figure S5).

Next, we sequenced the PCR products from the genomic DNA of each mutant to search for mutations within the targeted regions in three paralogs (BrVRN1a-c). Cloning the amplicons containing the target regions into plasmids and subsequent sequencing confirming the chimeric nature of the $\mathrm{T}_{1}$ plants. Interestingly, five (\#2-1,-2,-3,-8, and -13) mutant plants showed three types of mutations at two target sites in two genes (BrVRN1a, b) (Figure 2). Two types of mutations were found at target sites BrVRN1a-gRNA1 and -gRNA2 (A-insertion and C-insertion), and the 1-bp insertion type was most frequently 
identified. A type of mutation was also found at target site BrVRN1b-gRNA2 (A-insertion), and the 1-bp insertion type was most frequently identified. However, no mutations at the target sites BrVRN1c-gRNA1 and BrVRN1c-gRNA2 were generated in $\mathrm{T}_{1}$ plants (Figure 2). All types of frameshift mutations induced by CRISPR/Cas9 at target sites of BrVRN1 $a$ and BrVRN1b generated premature translation termination codons (Figure 3). Unfortunately, no mutations at target sites gRNA3 and gRNA4 in BrVRN1a were identified in $\mathrm{T}_{1}$ plants. This suggests that the mutations at these two target sites were not inherited from the $T_{0}$ generation to the $\mathrm{T}_{1}$ generation.

BrVRN1a (Bra022376-target)

\begin{tabular}{|c|c|}
\hline & gRNA1 \\
\hline Wt & CAGTACCTGAT-GGTCACGTTTGGCGTGTAGGACT \\
\hline \#2-1 & CAGTACCTGATAGGTCACGTTTGGCGTGTAGGACT \\
\hline \#2-2 & CAGTACCTGATAGGTCACGTTTGGCGTGTAGGACT \\
\hline \#2-3 & CAGTACCTGATAGGTCACGTTTGGCGTGTAGGACT \\
\hline \#2-8 & CAGTACCTGATAGGTCACGTTTGGCGTGTAGGACT \\
\hline \multirow[t]{2}{*}{ \#2-13 } & CAGTACCTGATAGGTCACGTTTGGCGTGTAGGACT \\
\hline & gRNA2 \\
\hline $\begin{array}{l}\text { Wt } \\
\# 2-1\end{array}$ & $\begin{array}{l}\text { TTTGTCGACCGTTACTCAATCCG-CATTGGCTATC } \\
\text { TTTGTCGACCGTTACTCAATCCGCCATTGGCTATC }\end{array}$ \\
\hline \#2-2 & TTTGTCGACCGTTACTCAATCCGCCATTGGCTATC \\
\hline \#2-3 & TTTGTCGACCGTTACTCAATCCGCCATTGGCTATC \\
\hline \#2-8 & TTTGTCGACCGTTACTCAATCCGCCATTGGCTATC \\
\hline \#2-13 & TTTGTCGACCGTTACTCAATCCGCCATTGGCTATC \\
\hline \multicolumn{2}{|r|}{ BrVRN1b (Bra037544) } \\
\hline & gRNA2 \\
\hline $\mathbf{W t}$ & TTGTTGACCGTTACTCAATCCG-CATTGGTTACC \\
\hline \#2-1 & TTGTTGACCGTTACTCAATCCGACATTGGTTACC \\
\hline \#2-2 & TTGTTGACCGTTACTCAATCCGACATTGGTTACC \\
\hline \#2-3 & TTGTTGACCGTTACTCAATCCGACATTGGTTACC \\
\hline \#2-8 & TTGTTGACCGTTACTCAATCCGACATTGGTTACC \\
\hline \#2-13 & TTGTTGACCGTTACTCAATCCGACATTGGTTACC \\
\hline
\end{tabular}

Figure 2. Target gene mutations by the multiplex CRISPR/Cas9 system in the $\mathrm{T}_{1}$ generation. The mutated DNA sequences of target regions are provided. Gene mutations are in red. Wt, untransformed wild-type plants; lanes \#2-2 to -8, selected GE1 lines, respectively.

\subsection{Stable Inheritance of Induced Mutations and Phenotypes of the Mutants}

To validate whether CRISPR/Cas9-mediated mutagenesis of BrVRN1s was linked to a late-bolting phenotype, we compared the flowering times of the three $\mathrm{T}_{1}$ mutant lines (\#1, \#2, and \#7) with that of wild-type plants under vernalization conditions. All three mutant lines had delayed flowering time (Figure S6 and Table 1). After a 60-day vernalization period, the average time to bolting after the end of the vernalization period was approximately nine days in wild-type plants, but 19-20 days in the CRISPR/Cas9mutagenized \#1 and \#2 $\mathrm{T}_{1}$ plants. In addition, after 40 days of vernalization, wild-type plants bolted 15-16 days after the end of vernalization, while the $T_{1}$ mutant \#7 plants were delayed by 8-11 days, bolting 23-27 days after the end of vernalization (Table 1). Thus, bolting time was delayed in all mutants regardless of cold treatment season and duration 
(Table 1), suggesting that the targeted gene-edits of BrVRN1s are sufficient to induce latebolting phenotypes in Chinese cabbage. In order to use the mutants showing delayed bolting as breeding material, we attempted to select mutants in which the transgenes had been removed and the mutations were homogeneous. We then analyzed $\mathrm{GE}_{2}$ generations of the two $\mathrm{GE}_{1}$ lines that had the Cas9 gene removed (Figure S3) and selected two 'transgenefree' mutants (\#2-2 and \#2-8) for phenotypic analysis. We self-crossed the \#2-2 and \#2-8 $\mathrm{GE}_{1}$ plants to obtain $\mathrm{GE}_{2}$ seeds and analyzed 10 plants (20 total) from each line for their genotypes and bolting characteristics.

\section{BrVRN1a (Bra022376-target)}

\begin{tabular}{|c|c|c|}
\hline 1 & 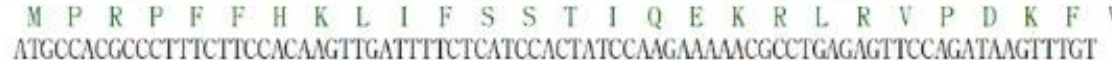 & 80 \\
\hline 1 & $\begin{array}{l}\text { TACGGTGCGGGAAAGAAGGTGTTCAACTAMAAGAGTAGGTGATAGGTTCTTTTTGCGGACTCTCAMGGTCTATTCAAACA } \\
\text { PAM }\end{array}$ & 80 \\
\hline 81 & 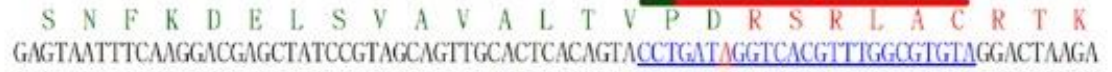 & 160 \\
\hline 81 & 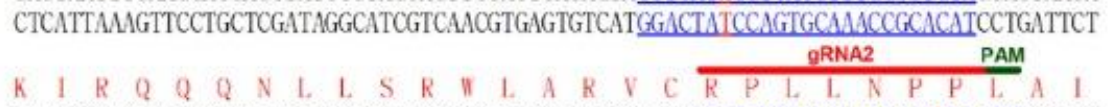 & 160 \\
\hline 161 & AAATCCGACAACAACAAAATCTACTTTCAAGATGGTTGGCAAGAGTTTGTCGACCGTTACTCAATCCGCCATTGGCTATC & 240 \\
\hline 161 & 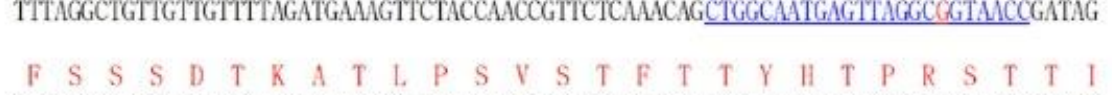 & 240 \\
\hline 241 & TICTCATCTTCAGATACGAAGGCAACTCTGCCTTCAGTGTCTACATTTACAACTTATCACACTCCGAGATCAACTACCAT & 320 \\
\hline 241 & 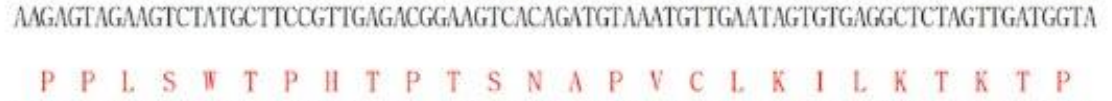 & 320 \\
\hline 321 & TOCTCCGCTCTCATGGACACCGCACACACCCACCTCAAACGCGCCCGTTTGTTTGAAGATCTTGAAGAOCAAGACGCOGG & 400 \\
\hline 321 & 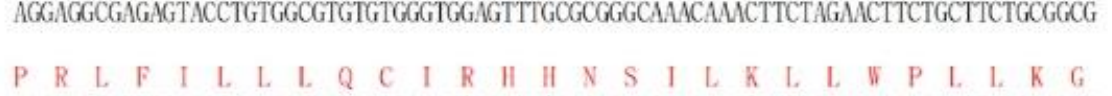 & 400 \\
\hline 401 & CGAGGTTGTTTATCCTTCTTCTTCAGTGTATCCGTCATCACAACAGCATCCTGAAGTTACTGTGGCCGCTATTAAAGGGT & 480 \\
\hline 401 & 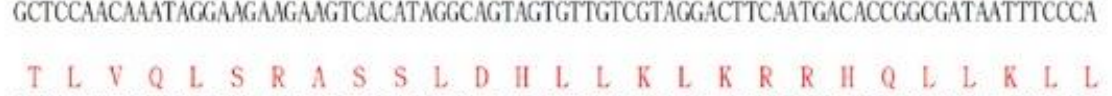 & 480 \\
\hline 481 & AOGCTAGTCCAGCTATCCAGAGCTTCTTCGCTGGACCACCTGTTAAAGCTGAAGAGGCGACACCAACTCCTAAAGTTACT & 560 \\
\hline 481 & 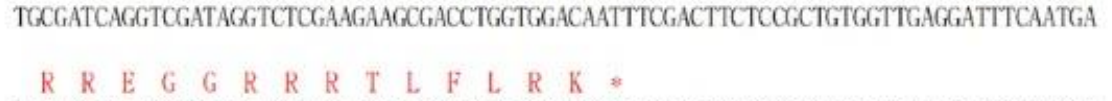 & 560 \\
\hline 56 & MGGAMGAGAGGGAGGAMGAMGAMGMACGCTGTTCCTGAGGMGTAMCTCATCTGCTCCGAGGGATGATGAOCCGGAGAG & \\
\hline 561 & ТTCTTCTCTCCCTCCTTCTTCTTCTTGCGACAAGGACTCCTTCATTTGAGTAGACGAGGCTCOCTACTACTGGGCCTCTC & 640 \\
\hline
\end{tabular}

\section{BrVRN1b (Bra037544)}

\begin{tabular}{|c|c|c|}
\hline & R $\quad V \quad P \quad P \quad D \quad K \quad F \quad V$ & \\
\hline 1 & ATGCCACGCCCTTTCITCCACAAGCTGATTTICTCATOCACTATCCAMGAMAAACGTCTGAGAGTICCAGATAAGTTTGT & 80 \\
\hline 1 & TACGGTGCGGGAAAGAAGGTTTCGACTMAMGAGTAGGTGATAGGTTCTTTTTGCAGACTCTCANGGTCTATTCAAACA & 80 \\
\hline & 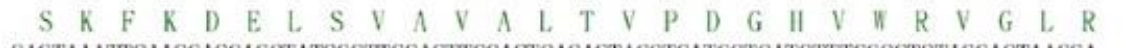 & \\
\hline 81 & GAGTAMATTCAMGGACGAGCTATCGGTTGCAGTTGCACTCACAGTACCTGATGGICATGTTTGGCGTGTAGGACTAAGGA & 160 \\
\hline 81 & $\begin{array}{c}\text { CTCATTTAAGTTCCTGCTCGATAGCCCAACGTCAACGTGAGTGTCATGGACTACCAGTACAAACCGCACATCCTGATTCCT } \\
\text { gRNA2 }\end{array}$ & 160 \\
\hline 161 & 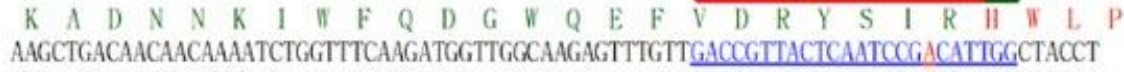 & 240 \\
\hline 161 & TTCGACTGTTGTTGTTTTAGACCAAAGTTCTACCAACCGTTCTCAAACAACTGGCAATGAGTTAGGCTGTAACCGATGGA & 240 \\
\hline & F D F & \\
\hline 241 & TTTGATTTTTAGATACGAAG & 320 \\
\hline 241 & AAACTAAAAATCTATGCTTCCGTTGAGACGGAAGTCGCAGATGTAAATGTTGAATAGTGTGAGGCTCTAGTTGATGGTAA & 320 \\
\hline
\end{tabular}

Figure 3. Nucleotide and deduced amino acid sequences of insertion variants of BrVRN1 homologs in \#2 GE1 mutant lines. Nucleotide residues are numbered starting with the methionine initiation codon (ATG). The deduced amino acid sequences are presented by a single letter code above the nucleotide sequence. The original amino acid sequences and changed codes are colored in green and red, respectively. The stop codon is denoted by an asterisk. 
Table 1. Phenotypes of flowering time in Chinese cabbage GE1 $\left(T_{1}\right)$ mutant plants after vernalization. GE1 mutant plants were exposed to low temperature $\left(4^{\circ} \mathrm{C}\right)$ for 40 or 60 days.

\begin{tabular}{cccc}
\hline Vernalization Period & Target Gene & GE1 Line & $\begin{array}{c}\text { Days to Visible Flowering } \\
\text { Bud in Plants }\end{array}$ \\
\hline \multirow{2}{*}{ 12 June-12 October 2020 (60 days) } & No gene targeted & Wt-1 10 & $9(9 \pm 0)^{\text {a }}$ \\
\cline { 2 - 4 } & BrVRN1 (multi-target) & $\# 1-1 \sim 19$ & $19-20\left(19.4 \pm 0.116^{* *}\right)$ \\
28 September-10 November 2020 & NrVRN1 (multi-target) & $\# 2-1 \sim 13$ & $19-20\left(19.2 \pm 0.104^{* *}\right)$ \\
\cline { 2 - 4 } (40 days) & BrVRN1 (multi-target) & Wt-1 5 & $15-16(15.6 \pm 0.245)$ \\
\hline
\end{tabular}

${ }^{a}$ (parentheses): The range of values obtained by mean \pm SE with $95 \%$ confidence limits ${ }^{* *} ; p$-value $<0.001$, Student's $t$-test).

To determine whether the BrVRN1 mutants could transmit the induced mutations and phenotypes to their progenies, we grew the $\mathrm{GE}_{2}$ progeny of the $\mathrm{GE}_{1} \# 2-2$ and \#2-8 lines under vernalization conditions. We examined Sanger sequencing results of three gene-specific amplicons from the $20 \mathrm{GE}_{2}$ plants and found that targeted mutagenesis of BrVRN1s induced by CRISPR/Cas9 was stably inherited and maintained consistent mutation types from the $\mathrm{GE}_{1}$ generation to the $\mathrm{GE}_{2}$ generation (Figure $\mathrm{S} 7$ ). The average time to bolting after 40-day vernalization was approximately 16 days in wild-type plants, but ranged from 37 to 59 days in the $\# 2-2$ and $\# 2-8 \mathrm{GE}_{2}$ plants, meaning that bolting was delayed by 21-43 days (Table 2). These results confirmed that the BrVRN1 mutant $\mathrm{GE}_{2}$ plants showed a delayed flowering phenotype under vernalization conditions, suggesting that the BrVRN1a and BrVRN1b knockout carried the controlled late-flowering trait in Chinese cabbage (Figure 4).

Table 2. Phenotypes of flowering time in Chinese cabbage GE2 mutant plants after vernalization. 'Transgene-free' GE2 plants were exposed to low temperature $\left(4^{\circ} \mathrm{C}\right)$ for 40 days.

\begin{tabular}{|c|c|c|c|}
\hline Vernalization Period & Target Gene & GE2 Line & $\begin{array}{l}\text { Days to Visible Flowering Bud } \\
\text { in Plants }\end{array}$ \\
\hline \multirow{3}{*}{21 January-2 March 2021 (40 days) } & No gene targeted & Wt-1 10 & $16(16 \pm 0)^{a}$ \\
\hline & $\begin{array}{c}B r V R N 1 \\
\text { (multi-target, transgene-free) }\end{array}$ & \#2-2-1 10 & $37-59\left(52.7 \pm 2.395^{* *}\right)$ \\
\hline & $\begin{array}{c}\text { BrVRN1 } \\
\text { (multi-target, transgene-free) }\end{array}$ & \#2-8-1 10 & $38-56\left(48.3 \pm 2.408^{* *}\right)$ \\
\hline
\end{tabular}

a (parentheses): The range of values obtained by mean \pm SD with $95 \%$ confidence limits $\left({ }^{* *} ; p\right.$-value $<0.001$, Student's $t$-test).

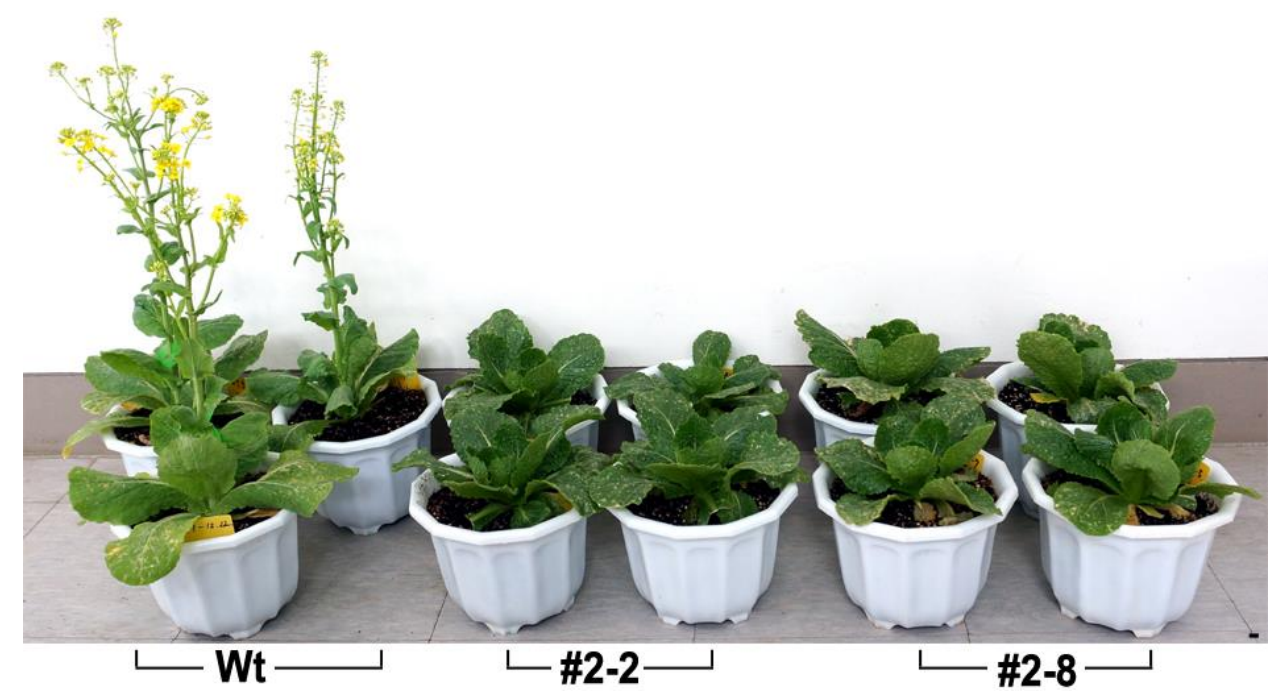

Figure 4. Flowering-time phenotype in 'transgene-free' BrVRN1 GE2 mutant lines. Pictures were taken 31 days at $25^{\circ} \mathrm{C}$ after a 40-day exposure to $4{ }^{\circ} \mathrm{C}$. Wt, untransformed wild-type plants; \#2-2 and \#2-8, selected 'transgene-free' GE2 mutant lines, respectively. 


\subsection{Expression Patterns of Floral Regulators in GE2 Mutant Plants}

Because the $B r V R N 1 \mathrm{GE}_{2}$ mutants displayed late-flowering phenotypes, we considered the possibility that $B r V R N 1$ s may regulate the expression of other floral genes, such as FLC1 and FT [23]. Therefore, we analyzed the expression patterns of BrFLC1 and BrFT in the leaves of vernalized and unvernalized wild-type and 'transgene-free' $\mathrm{GE}_{2}$ mutant plants with different flowering times using qPCR (Figure 5). Unvernalized wild-type Chinese cabbage showed high $B r F L C 1$ expression, whereas BrFT expression was undetectable, probably because of the high level of BrFLC1 expression. BrFLC1 expression was reduced in the wild-type plant during a 40-day cold treatment. BrFT expression was undetectable before vernalization, but began to increase towards the end of vernalization; in general, the BrFT expression level was inversely proportional to that of $B r F L C$ [32]. In $\mathrm{GE}_{2}$ mutant plants, the expression of $B r F L C 1$ decreased more slowly than in wild-type plants and remained detectable after vernalization. In addition, $F T$ expression was never observed in the mutants regardless of vernalization status. However, $B r V R N 1 a$ expression in mutants at the RNA level was similar to that of the wild type, occurring only after vernalization (Figure S8). These results revealed that the altered patterns of BrFLC1 and BrFT expression induced by $B r V R N 1$ mutations could result in the late flowering time phenotypes of mutant plants. These data indicate that the BrVRN1s are important determinants of vernalizationresponsive flowering time through their regulation of $B r F L C 1$ and $B r F T$ expression in Chinese cabbage.

\subsection{Analysis of Potential Off-Target Changes}

To confirm the specificity of BrVRN1 gene editing via CRISPR/Cas9 in Chinese cabbage, and to avoid affecting the phenotypic statistics by including off-target mutations when identifying homologous mutants, we analyzed the potential off-target effects based on SNP and indel proportions in the $10 \mathrm{GE}_{2}$ mutant plants (five plants each of the \#2-2 and \#2-8 lines) using NGS (Tables S3 and S5). All of the examined potential off-target sites possessed mismatches of only 1-3 bp compared with the on-target guide sequences. We did not observe any mutations in the potential off-target sites we examined in $\mathrm{GE}_{2}$ plants (Table 3). Also, the mutation types (BrVRN1a; A-insertion and C-insertion, BrVRN1b; A-insertion) in $\mathrm{GE}_{1}$ mutants (\#2-2 and \#2-8) were inherited without any transgenic elements in the $\mathrm{GE}_{2}$ generation (Tables 4 and 5). In this experiment, we identified homozygous double mutations (BrVRN1a and BrVRN1b), but no heterozygous mutations in the $10 \mathrm{GE}_{2}$ mutant (Table 5).

BrFLC1

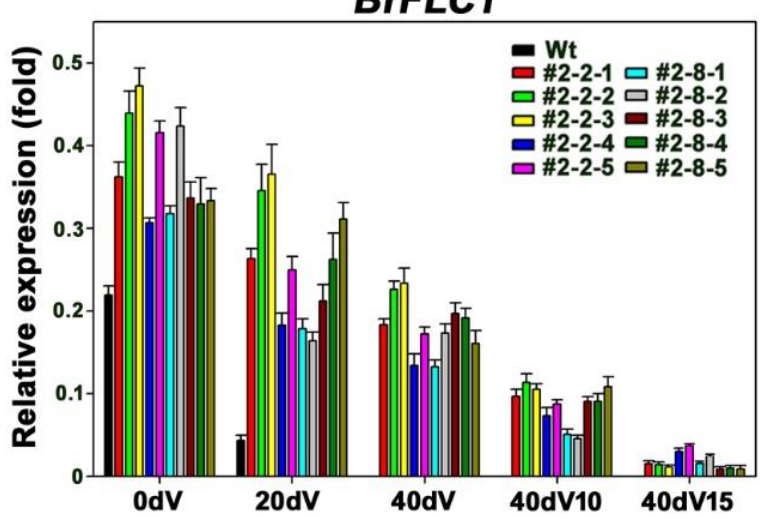

BrFT

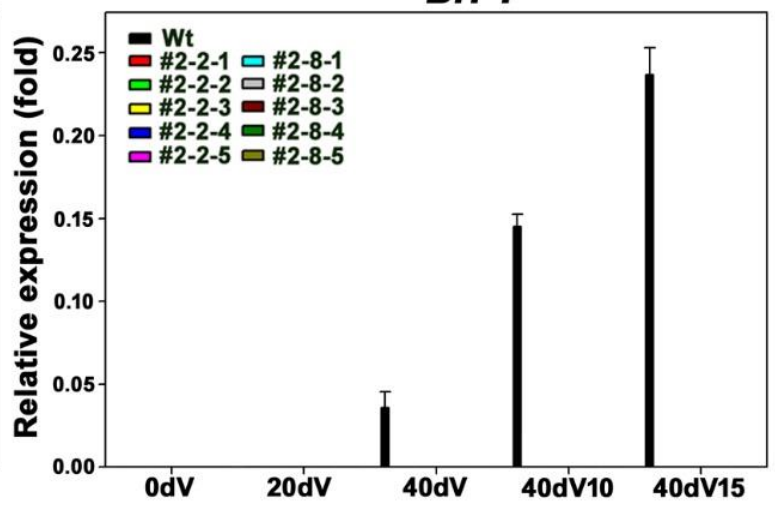

Figure 5. Expression patterns of floral regulator genes in 'transgene-free' BrVRN1 mutant GE2 lines. BrFLC, B. rapa FLOWERING LOCUS C; FT, FLOWERING LOCUS T. 0dV, 20 day-old plants before cold treatment $\left(4{ }^{\circ} \mathrm{C}\right) ; 20 \mathrm{dV}, 20-\mathrm{day}$ exposure to $4{ }^{\circ} \mathrm{C} ; 40 \mathrm{dV}, 40$-day exposure to $4{ }^{\circ} \mathrm{C} ; 40 \mathrm{dV} 10$ and $40 \mathrm{dV} 15,10$ days and 15 days at $25{ }^{\circ} \mathrm{C}$ after a 40 -day exposure to $4{ }^{\circ} \mathrm{C}$, respectively. Wt, untransformed wild-type plants; lanes \#2-2-1 to \#2-8-10, selected 'transgene-free' GE2 mutant lines, respectively. 
Table 3. Effect of chromatin structure on Cas9 activity at off-target sites of the 'transgene-free' GE2 mutant plants.

\begin{tabular}{|c|c|c|c|c|c|}
\hline Target & Target Sequence & Mismatch & $\begin{array}{c}\text { Number of Found } \\
\text { Targets }\end{array}$ & $\begin{array}{c}\text { Number of SNP } \\
\text { Positions }\end{array}$ & $\begin{array}{c}\text { Number of In/Del } \\
\text { Positions }\end{array}$ \\
\hline gRNA1 & ACACGCCAAACGTGACCATCNGG & $\begin{array}{l}1 \\
2 \\
3\end{array}$ & $\begin{array}{l}0 \\
0 \\
1\end{array}$ & $\begin{array}{l}0 \\
0 \\
0\end{array}$ & $\begin{array}{l}0 \\
0 \\
0\end{array}$ \\
\hline gRNA2 & GACCGTTACTCAATCCGCATNGG & $\begin{array}{l}1 \\
2 \\
3\end{array}$ & $\begin{array}{l}0 \\
0 \\
0\end{array}$ & $\begin{array}{l}0 \\
0 \\
0\end{array}$ & $\begin{array}{l}0 \\
0 \\
0\end{array}$ \\
\hline gRNA3 & AGAAGAAGGATAAACAACCTNGG & $\begin{array}{l}1 \\
2 \\
3\end{array}$ & $\begin{array}{l}0 \\
0 \\
6\end{array}$ & $\begin{array}{l}0 \\
0 \\
1\end{array}$ & $\begin{array}{l}0 \\
0 \\
0\end{array}$ \\
\hline gRNA4 & ATAGCGGCCACAGTAACTTCNGG & $\begin{array}{l}1 \\
2 \\
3 \\
\end{array}$ & $\begin{array}{l}0 \\
0 \\
0 \\
\end{array}$ & $\begin{array}{l}0 \\
0 \\
0 \\
\end{array}$ & $\begin{array}{l}0 \\
0 \\
0 \\
\end{array}$ \\
\hline total & & & 7 & 1 & 0 \\
\hline
\end{tabular}

Excluded the on-target sites searched of three BrVRN1 genes. Nucleotides in red represent PAM sequence.

Table 4. Statistics of alignment to BrVRN1a-4gRNAs vector.

\begin{tabular}{cccc}
\hline Line & No. of Total Trimmed Reads $* \mathbf{1}$ & No. of Mapped Reads ${ }^{\mathbf{2}}$ & Mapped Region *3 (\%) \\
\hline WT & $143,832,424$ & $24(0.00 \%)$ & $374(2.81 \%)$ \\
$\# 2-2-1$ & $110,834,798$ & $1(0.00 \%)$ & $0(0.00 \%)$ \\
$\# 2-2-2$ & $144,407,538$ & $13(0.00 \%)$ & $0(0.00 \%)$ \\
$\# 2-2-3$ & $129,575,654$ & $6(0.00 \%)$ & $0(0.00 \%)$ \\
$\# 2-2-4$ & $160,433,726$ & $8(0.00 \%)$ & $0(0.00 \%)$ \\
$\# 2-2-5$ & $120,246,026$ & $4(0.00 \%)$ & $0(0.00 \%)$ \\
$\# 2-8-1$ & $130,463,146$ & $4(0.00 \%)$ & $0(0.00 \%)$ \\
$\# 2-8-2$ & $153,956,546$ & $7(0.00 \%)$ & $0(0.00 \%)$ \\
$\# 2-8-3$ & $151,410,950$ & $2(0.00 \%)$ & $0(0.00 \%)$ \\
$\# 2-8-4$ & $160,952,626$ & $6(0.00 \%)$ & $0(0.00 \%)$ \\
\hline $2-5$ & $126,426,790$ & $12(0.00 \%)$ & $0(0.00 \%)$ \\
\hline
\end{tabular}

${ }^{* 1}$ No. of Total trimmed reads: Total number of clean reads used for read alignment through pre-processing. ${ }^{* 2}$ No. of Mapped reads: When clean reads are aligned, the number of reads mapped to the vector sequence. ${ }^{* 3}$ Mapped region: Compared to the vector $13,301 \mathrm{bp}$ sequence, the base pair of the region covered by read alignment.

Table 5. Summary of zygosity and genotype of BrVRN1 mutations in the 'transgene-free' GE2 mutant plants.

\begin{tabular}{|c|c|c|c|c|c|c|c|c|c|c|c|}
\hline \multirow[b]{2}{*}{ Line } & \multirow[b]{2}{*}{ Target } & \multirow{2}{*}{$\begin{array}{l}\text { Type of } \\
\text { Mutation }\end{array}$} & \multicolumn{3}{|c|}{ BrVRN1a } & \multicolumn{3}{|c|}{$B r V R N 1 b$} & \multicolumn{3}{|c|}{ BrVRN1c } \\
\hline & & & Reads & $\begin{array}{c}\text { Read } \\
\text { Rate (\%) }\end{array}$ & Zygosity & Reads & $\begin{array}{c}\text { Read } \\
\text { Rate (\%) }\end{array}$ & Zygosity & Reads & $\begin{array}{c}\text { Read } \\
\text { Rate (\%) }\end{array}$ & Zygosity \\
\hline \multirow{4}{*}{$\# 2-2-1 \sim 5$} & gRNA1 & $\begin{array}{c}\mathrm{Wt} \\
+\mathrm{A} \\
\text { Total }\end{array}$ & $\begin{array}{c}10 \\
103 \\
113\end{array}$ & 91.15 & Homozygous & $\begin{array}{c}115 \\
- \\
115\end{array}$ & 0 & $\mathrm{Wt}$ & $\begin{array}{c}171 \\
- \\
171\end{array}$ & 0 & $\mathrm{Wt}$ \\
\hline & gRNA2 & $\begin{array}{c}\mathrm{Wt} \\
+\mathrm{C} /+\mathrm{A} \\
\text { Total }\end{array}$ & $\begin{array}{c}11 \\
110 \\
121\end{array}$ & $\begin{array}{c}90.90 \\
-\end{array}$ & Homozygous & $\begin{array}{c}4 \\
93 \\
97\end{array}$ & 95.87 & Homozygous & $\begin{array}{c}165 \\
- \\
165\end{array}$ & 0 & $\mathrm{Wt}$ \\
\hline & gRNA3 & $\begin{array}{c}\text { Wt } \\
\text { SNP/indel } \\
\text { Total }\end{array}$ & $\begin{array}{c}147 \\
- \\
147 \\
\end{array}$ & 0 & $\mathrm{Wt}$ & $\begin{array}{l}- \\
- \\
-\end{array}$ & - & - & $\begin{array}{l}- \\
- \\
-\end{array}$ & - & - \\
\hline & gRNA4 & $\begin{array}{c}\text { Wt } \\
\text { SNP/indel } \\
\text { Total }\end{array}$ & $\begin{array}{c}124 \\
- \\
124\end{array}$ & 0 & $\mathrm{Wt}$ & $\begin{array}{l}- \\
- \\
-\end{array}$ & - & - & $\begin{array}{l}- \\
- \\
-\end{array}$ & - & - \\
\hline \multirow{4}{*}{ \#2-8-1 5 } & gRNA1 & $\begin{array}{c}\mathrm{Wt} \\
+\mathrm{A} \\
\text { Total }\end{array}$ & $\begin{array}{c}5 \\
115 \\
120\end{array}$ & 95.83 & Homozygous & $\begin{array}{c}108 \\
- \\
108\end{array}$ & 0 & $\mathrm{Wt}$ & $\begin{array}{c}171 \\
- \\
171\end{array}$ & 0 & $\mathrm{Wt}$ \\
\hline & gRNA2 & $\begin{array}{c}\mathrm{Wt} \\
+\mathrm{C} /+\mathrm{A} \\
\text { Total }\end{array}$ & $\begin{array}{c}11 \\
135 \\
146\end{array}$ & 92.46 & Homozygous & $\begin{array}{c}8 \\
121 \\
129\end{array}$ & 93.80 & Homozygous & $\begin{array}{c}155 \\
- \\
155\end{array}$ & 0 & $\mathrm{Wt}$ \\
\hline & gRNA3 & $\begin{array}{c}\mathrm{Wt} \\
\text { SNP/indel } \\
\text { Total }\end{array}$ & $\begin{array}{c}151 \\
- \\
151 \\
\end{array}$ & 0 & $\mathrm{Wt}$ & $\begin{array}{l}- \\
- \\
-\end{array}$ & - & - & $\begin{array}{l} \\
- \\
-\end{array}$ & - & - \\
\hline & gRNA4 & $\begin{array}{c}\text { Wt } \\
\text { SNP/indel } \\
\text { Total }\end{array}$ & $\begin{array}{c}149 \\
- \\
149\end{array}$ & 0 & $\mathrm{Wt}$ & $\begin{array}{l}- \\
- \\
-\end{array}$ & - & - & $\begin{array}{l}- \\
- \\
-\end{array}$ & - & - \\
\hline
\end{tabular}

* Read rate indicates the percentage of the number of mutations in the total mapped read count. Plus symbol denotes insertion. Homologous: read rate $\geq 90 \%$ and heterozygous: $40 \% \leq$ read rate $<90 \%$. 


\section{Discussion}

The transition from vegetative to reproductive growth is a key developmental switch in the life cycle of flowering plants. Flowering is regulated by a complex regulatory network that modulates flowering time in response to various environmental stimuli and developmental statuses [32,43]. Chinese cabbage is a typical vernalization-sensitive plant. Genetic analyses have identified several genes, including VERNALIZATION1 (VRN1), involved in the control of flowering time in Chinese cabbage during vernalization $[23,25,41,44]$.

$V R N 1$ encodes a DNA binding protein containing two plant-specific B3 domains that is required for the increase in H3K27me3 (trimethylation of lysine 27 in histone H3) epigenetic marks that causes transcriptional repression of FLC during prolonged cold treatment $[23,26]$. In previous studies, expression levels of AtVRN1 and AtVRN2 were not affected by vernalization in Arabidopsis [22,23]. In contrast to Arabidopsis, in Chinese cabbage one of the three BrVRN1 paralogs (Bra022376) was upregulated by cold treatment, whereas the other two (Bra037544 and Bra001729) were downregulated [25,41]. These results suggest that the flowering pathway in Chinese cabbage is somehow different and more complex than that of Arabidopsis [25,41]. Despite the importance of VRN1 genes in controlling vernalization-responsive flowering time, phenotypic effects of the BrVRN1 genes in Chinese cabbage have not been fully investigated.

The CRISPR/Cas9 system has been reliable means to perform functional studies on multi-gene clusters of unknown function and is becoming one of the most effective tools for creating desirable phenotypes in crop plants. In this study, we assessed the molecular variation in the flowering time of Chinese cabbage via CRISPR/Cas9-mediated mutagenesis of $B r V R N 1$ genes. Among the three BrVRN1 genes, we chose four target sites in the second exon of BrVRN1a (Figures 1 and S1 and Table S1) [25,41]. This multiplex CRISPR/Cas9 system-generated target gene mutations with a highly diverse pattern of indel mutations in the $\mathrm{T}_{0}$ generation. CRISPR/Cas9 editing using constitutively strong promoters such as CaMV $35 S$ may generate unwanted somatic mutations in various tissues and growth periods. The various mutations induced through CRISPR/Cas9 in the $\mathrm{T}_{0}$ generations may then be unstably inherited, and it is, therefore, difficult to maintain consistent mutation types between the $T_{0}$ and $T_{1}$ generations. These undesired and unstable mutations in Chinese cabbage can be segregated out of the genome via self-pollination [45]. Notably, not all $\mathrm{T}_{0}$ plants were capable of generating seeds, with only three out of ten edited lines (\#1, \#2, \#7 lines) forming seeds (Figure S2 and Table S4). By deep sequencing of $\mathrm{T}_{1}$ plants from the \#2 line without transgenes, we verified the presence of $\mathrm{A}$ and $\mathrm{C}$ base insertions at the gRNA1 and gRNA2 target sites ( Figures 2 and S5), confirming that the CRISPR/Cas9-induced mutations were passed down from the $\mathrm{T}_{0}$ to the $\mathrm{T}_{1}$ generation. In addition, targeted mutations in two BrVRN1 orthologs (BrVRN1a and BrVRN1b) in the $\mathrm{T}_{1}$ heterozygous mutant lines were stably transmitted to the $\mathrm{GE}_{2}$ generation (Figures 2 and $\mathrm{S} 7$ and Table 4). These mutations, caused by base insertions in the coding regions, were expected to inactivate the BrVRN1a and BrVRN1b proteins by causing frameshifts (Figure 3). In contrast, no mutations at target sites BrVRN1a gRNA3 or gRNA4 or BrVRN1c gRNA1 or gRNA2 were identified in the $\mathrm{T}_{1}$ and $\mathrm{GE}_{2}$ mutant plants (Figures 2 and $\mathrm{S} 5$ and Table 5). This suggests that the gene targeting efficiency of sgRNAs may be affected by their relative position in the expression cassette and the chromosome structure of targeted genes, as has also been observed in other plant species [31,46]. Taken together, our results demonstrate the feasibility of introducing transmissible mutations induced by CRISPR/Cas9 through the propagation of stable transgenic plants, which could be widely used for reverse genetics in Chinese cabbage.

In applying CRISPR/Cas9 gene editing, it is important to consider off-target sites, and the homology between sgRNAs and candidate off-target sites has been reported to be the main factor influencing off-target mutations $[47,48]$. To examine the specificity of CRISPR/Cas9 in Chinese cabbage and avoid confounding our phenotype statistics by including off-target sites, we investigated the off-target regions of four target sites of BrVRN1 through NGS analysis. We observed no mutations at any of the off-target 
sites (Table 3), most likely as a result of careful target selection. The risk of off-target edits by CRISPR/Cas9 in Chinese cabbage may also be low in general on account of the low frequency of somatic mutations in tissue-culture-based transformation [48]. In addition, undesired off-target mutations in plants could be eliminated by hybridization [45]. Therefore, we predicted that the complex mutation patterns of the BrVRN1 in $\mathrm{T}_{0}$ plants could be eliminated by hybridization (Figures S2 and 2).

Chinese cabbage possesses three BrVRN1 genes, but it is not known whether all three are involved in controlling flowering time [25,41]. However, the BrVRN1a and $B r V R N 1 b$ double-mutant plants did display a delayed flowering phenotype (Figure 4 and Table 2). Although our data do not indicate whether the BrVRN1b gene directly or indirectly influenced late-flowering phenotypes, they do suggest that the induced lateflowering phenotypes by the double-mutations of $B r V R N 1$ genes attests to the complexity underlying multiple signalling networks. Therefore, further experiments are required to define how much the $B r V R N 1$ genes contribute to the regulation of flowering time by vernalization in comparison with $B r F L C$ genes. However, the frameshift mutations induced by CRISPR/Cas9 at two target sites of BrVRN1 generated premature translation termination codons through amino acid substitution in the corresponding protein (Figure 3). This result suggests that the mutated genes were not translated as complete proteins containing two B3 domains, resulting in a loss of protein function. Therefore, their inability to suppress FLC expression in warm conditions following prolonged cold exposure resulted in a late-flowering phenotype [23,44]. In this study, the mutants for which BrVRN1 gene editing was confirmed showed a delayed flowering time in each generation (from the $T_{0}$ to the $T_{2}$ generation), regardless of the season or the low-temperature treatment period (Tables 1 and 2). In addition, the bolting time of $\mathrm{GE}_{2}$ mutant plants ranged from 37 to 59 days, whereas the $\mathrm{GE}_{1}$ mutant plants required from 23 to 27 days, which may have been caused by converting heterozygous mutations in the targeted genes to homozygous using selfing-crossing (Table 5). Our results suggest that BrVRN1 genes play an important role in the regulation of flowering time in Chinese cabbage by regulating the expression of the floral repressor FLC and floral integrator FT (Figure 5). In addition, these results suggest the possibility of developing breeding material with a delayed flowering time in Brassicaceae with a similar flowering pathway mechanism using VRN1 gene knockouts.

Recently, genome-editing technology has provided a new approach for developing crops that can replace genetically modified organisms (GMOs), whose safety has been debated [45]. The CRISPR/Cas9 system can accurately generate site-directed mutations in specific genes. The exogenous transgenes (Cas9, sgRNA, promoters, and selectable markers) inserted into a plant genome by Agrobacterium-mediated transformation can be removed in later generations via genetic segregation through selfing-crossing or hybridization approaches. These 'transgene-free' mutants have been generated by CRISPR/Cas9 editing in many plant species, such as Arabidopsis [49,50], rice [51,52], wheat [53], tomato [54], and soya bean [45]. In the present study, we obtained 'transgenefree' targeted genome-modified Chinese cabbage that was homozygous for the null alleles of endogenous BrVRN1a and BrVRN1b without any transgenic elements in the $\mathrm{GE}_{1}$ and $\mathrm{GE}_{2}$ generations (Figures S3 and S4, Tables 4 and 5). Therefore, 'transgene-free' BrVRN1 mutants can provide breeding materials for developing Brassica crops with delayed flowering time. Chinese cabbage is very sensitive to low temperatures, which limits its geographical range of cultivation, and our study may contribute to expanded regional introduction and domestication of this species.

\section{Conclusions}

In conclusion, this is the first report of the development of a Chinese cabbage strain with a delayed flowering time trait through $B r V R N 1$ gene editing using a multiplex CRISPR/Cas9 system. BrVRN1-specific gene editing notably delayed flowering times and induced the production of heritable mutations. Taken together, our data indicate that $B r V R N 1$ acts as a positive regulator of the induction of flowering in Chinese cabbage, thus 
raising the possibility that this may serve as a useful genetic source for crop improvement with respect to local environments and climate change.

Supplementary Materials: The following are available online at https:/ /www.mdpi.com/article/10 .3390 /agriculture11121286/s1, Figure S1. Comparison of the nucleotide sequences of three BrVRN1 genes with target sites of CRISPR/Cas9. Figure S2. Genome-editing analysis of $\mathrm{T}_{0}$ plants by deepsequencing. Figure S3. The confirmation of the presence of hygromycin resistant gene $(h p h)$ and Cas 9 transgenes using genomic PCR analysis in $\mathrm{T}_{1}$ transgenic lines. Figure $\mathrm{S} 4$. The confirmation of the presence of Cas 9 transgenes using genomic PCR analysis in 'transgene-free' BrVRN1 mutant GE2 lines. Figure S5. Genome-editing analysis of $\mathrm{T}_{0}$ lines by deep-sequencing. Figure S6. Floweringtime phenotype in BrVRN1 mutant GE1 plants. Figure S7. Target gene mutations by the multiplex CRISPR/Cas9 system in the GE2 generation. Figure S8. Expression patterns of BrVRN1a in 'transgenefree' BrVRN1 mutant GE2 lines. Table S1. Features of BrVRN1 genes used in this study. Table S2. Summary of Brassica rapa L. (v3.0) reference genome. Table S3. Statistics of target four-gRNA position on the reference v3 genome. Table S4. CRISPR/Cas9-mediated targeted mutagenesis of BrVRN1 in the $\mathrm{T}_{0}$ generation. Table S5. Statistics of final trimmed whole genome resequencing data from 'transgene-free' BrVRN1 mutant GE2 lines.

Author Contributions: Y.-H.L. conceived and designed the research. J.K.H. and J.P. performed experiments. J.K.H., E.J.S. and S.R.P. collected and analyzed the data. J.K.H. and Y.-H.L. wrote the manuscript. All authors have read and agreed to the published version of the manuscript.

Funding: This work was carried out with the support of "Research Program for Agricultural Biotechnology (PJ014174)", National Institute of Agricultural Science, Rural Development Administration, Republic of Korea. This study was supported by 2021 the RDA Fellowship Program of National Institute of Agricultural Science, Rural Development Administration, Republic of Korea.

Institutional Review Board Statement: Not applicable.

Informed Consent Statement: Not applicable.

Data Availability Statement: Not applicable.

Conflicts of Interest: The authors declare no conflict of interest.

\section{References}

1. Jung, H.J.; Dong, X.; Park, J.I.; Thamilarasan, S.K.; Lee, S.S.; Kim, Y.K.; Lim, Y.P.; Nou, I.S.; Hur, Y. Genome-wide transcriptome analysis of two contrasting Brassica rapa doubled haploid lines under cold-stresses using Br135K oligomeric chip. PLoS ONE 2014, 9, e106069. [CrossRef]

2. Li, J.; Zhao, X.; Nishimura, Y.; Fukumoto, Y. Correlation between bolting and physiological properties in Chinese cabbage (Brassica rapa L. Pekinensis group). J. Jpn. Soc. Hortic. Sci. 2010, 79, 294-300. [CrossRef]

3. Elers, B.; Wiebe, H.-J. Flower formation of chinese cabbage. I. Response to vernalization and photoperiods. Sci. Hortic. 1984, 22, 219-231. [CrossRef]

4. Mero, C.E.; Honma, S. Inheritance of bolting resistance in an intraspecific Chinese cabbage x turnip cross. HORTSCIENCE 1985, 20, 881-882.

5. Jung, C.; Müller, A.E. Flowering time control and applications in plant breeding. Trends Plant Sci. 2009, 14, 563-573. [CrossRef] [PubMed]

6. Simpson, G.G.; Dean, D. Arabidopsis, the Resetta stone of flowering time? Science 2002, 296, 285-289. [CrossRef]

7. Baurle, I.; Dean, C. The timing of developmental transitions in plants. Cell 2006, 125, 655-664. [CrossRef]

8. Amasino, R. Vernalization, competence, and the epigenetic memory of winter. Plant Cell 2004, 16, 2553-2559. [CrossRef]

9. Amasino, R. Seasonal and developmental timing of flowering. Plant J. 2010, 61, 1001-1013. [CrossRef]

10. Shea, D.J.; Itabashi, E.; Takada, S.; Fukai, E.; Kakizaki, T.; Fujimoto, R.; Okazaki, K. The role of FLOWERING LOCUS C in vernalization of Brassica: The importance of vernalization research in the face of climate change. Crop Pasture Sci. 2018, 69, 30-39. [CrossRef]

11. Su, T.; Wang, W.; Li, P.; Zhang, B.; Li, P.; Xin, X.; Sun, H.; Yu, Y.; Zhang, D.; Zhao, X.; et al. A genomic variation map provides insights into the genetic basis of spring Chinese cabbage (Brassica rapa ssp. pekinensis) selection. Mol. Plant 2018, 11, 1360-1376. [CrossRef]

12. Geraldo, N.; Baurle, I.; Kidou, S.; Hu, X.; Dean, C. FRIGIDA delays flowering in Arabidopsis via a cotranscriptional mechanism involving direct interaction with the nuclear Cap-Binding Complex. Plant Physiol. 2009, 150, 1611-1618. [CrossRef] 
13. Searle, I.; He, Y.; Turck, F.; Vincent, C.; Fornara, F.; Krober, S.; Amasino, R.A.; Coupland, G. The transcription factor FLC confers a flowering response to vernalization by repressing meristem competence and systemic signaling in Arabidopsis. Genes Dev. 2006, 20, 898-912. [CrossRef]

14. Michaels, S.D.; Amasino, R.M. FLOWERING LOCUS C encodes a novel MADS domain protein that acts as a repressor of flowering. Plant Cell 1999, 11, 949-956. [CrossRef] [PubMed]

15. Blümel, M.; Dally, N.; Jung, C. Flowering time regulation in crops-what did we learn from Arabidopsis? Curr. Opin. Biotechnol. 2015, 32, 121-129. [CrossRef] [PubMed]

16. Sheldon, C.C.; Burn, J.E.; Perez, P.P.; Metzger, J.; Edwards, J.A.; Peacock, W.J.; Dennis, E.S. The FLF MADS box gene: A repressor of flowering in Arabidopsis regulated by vernalization and methylation. Plant Cell. 1999, 11, 445-458. [CrossRef] [PubMed]

17. Lee, I.; Amasino, R.M. Effect of vernalization, photoperiod, and light quality on the flowering phenotype of Arabidopsis plants containing the FRIGIDA gene. Plant Physiol. 1995, 108, 157-162. [CrossRef]

18. Greb, T.; Mylne, J.S.; Crevillen, P.; Geraldo, N.; An, H.; Gendall, A.R.; Dean, C. The PHD finger protein VRN5 functions in the epigenetic silencing of Arabidopsis FLC. Curr. Biol. 2007, 17, 73-78. [CrossRef]

19. He, Y.; Amasino, R.M. Role of chromatin modification in flowering time control. Trends Plant Sci. 2005, 10, 30-35. [CrossRef]

20. Wood, C.C.; Robertson, M.; Tanner, G.; Peacock, W.J.; Dennis, E.S.; Helliwell, C.A. The Arabidopsis thaliana vernalization response requires a polycomb-like protein complex that also includes VERNALIZATION INSENSITIVE 3. Proc. Natl. Acad. Sci. USA 2006, 103, 14631-14636. [CrossRef]

21. Sung, S.; Amasino, R.M. Vernalization and epigenetics: How plants remember winter. Curr. Opin. Plant Biol. 2004, 7, 4-10. [CrossRef]

22. Gendall, A.R.; Levy, Y.Y.; Wilson, A.; Dean, C. The VERNALIZATION 2 gene mediates the epigenetic regulation of vernalization in Arabidopsis. Cell 2001, 107, 525-535. [CrossRef]

23. Levy, Y.Y.; Mesnage, S.; Mylne, J.S.; Gendall, A.R.; Dean, C. Multiple roles of Arabidopsis VRN1 in vernalization and flowering time control. Science 2002, 297, 243-246. [CrossRef] [PubMed]

24. Sheldon, C.C.; Finnegan, E.J.; Dennis, E.S.; Peacock, W.J. Quantitative effects of vernalization on FLC and SOC1 expression. Plant J. 2006, 45, 871-883. [CrossRef] [PubMed]

25. Akter, A.; Miyazaki, J.; Shea, D.J.; Nishida, N.; Takada, S.; Miyaji, N.; Mehraj, H.; Shimizu, M.; Doullah, M.A.; Takasaki-Yasuda, T.; et al. Gene expression analysis in response to vernalization in Chinese cabbage (Brassica rapa L.). Hortic. J. 2020, 89, 268-277. [CrossRef]

26. Song, X.; Duan, W.; Huang, Z.; Liu, G.; Wu, P.; Liu, T.; Li, Y.; Hou, X. Comprehensive analysis of the flowering genes in Chinese cabbage and examination of evolutionary pattern of co-like genes in plant kingdom. Sci. Rep. 2015, 5, 14631. [CrossRef]

27. Shea, D.J.; Nishida, N.; Takada, S.; Itabashi, E.; Takahashi, S.; Akter, A.; Miyaji, N.; Osabe, K.; Mehraj, H.; Shimizu, M.; et al. Long noncoding RNAs in Brassica rapa L. Following vernalization. Sci. Rep. 2019, 9, 9302. [CrossRef]

28. Jeong, S.; Ahn, H.; Ryu, J.; Oh, Y.; Sivanandhan, G.; Won, K.-H.; Park, Y.; Kim, J.-S.; Lim, Y.P.; Kim, S.-G. Generation of earlyflowering Chinese cabbage (Brassica rapa spp. Pekinensis) through CRISPR/Cas9-mediated genome editing. Plant Biotechnol. Rep. 2019, 13, 491-499. [CrossRef]

29. Murovec, J.; Gucek, K.; Bohanec, B.; Avbelj, M.; Jerala, R. DNA-free genome editing of Brassica oleracea and B. rapa protoplasts using CRISPR-Cas9 ribonucleoprotein complexes. Front. Plant Sci. 2018, 9, 1594. [CrossRef]

30. Park, J.; Bae, S.; Kim, J.-S. Cas-Designer: A web-based tool for choice of CRISPR-Cas9 target sites. Bioinformatics 2015, 31, 4014-4016. [CrossRef]

31. Zhang, Z.; Mao, Y.; Ha, S.; Liu, W.; Botella, J.R.; Zhu, J.-K. A multiplex CRISPR/Cas9 platform for fast and efficient editing of multiple genes in Arabidopsis. Plant Cell Rep. 2016, 35, 1519-1533. [CrossRef] [PubMed]

32. Kim, S.Y.; Park, B.S.; Kwon, S.J.; Kim, J.; Lim, M.H.; Park, Y.D.; Kim, D.Y.; Suh, S.C.; Jin, Y.M.; Ahn, J.H.; et al. Delayed flowering time in Arabidopsis and Brassica rapa by the overexpression of FLOWERING LOCUS C (FLC) homologs isolated from Chinese cabbage (Brassica rapa L. ssp. pekinensis). Plant Cell Rep. 2007, 26, 327-336. [CrossRef]

33. Lee, M.-K.; Kim, H.-S.; Kim, J.-S.; Kim, S.-H.; Park, Y.-D. Agrobacterium-mediated transformation system for large-scale production of transgenic Chinese cabbage (Brassica rapa L. ssp. pekinensis) plants for insertional mutagenesis. J. Plant Biol. 2004, 47, 300-306. [CrossRef]

34. Jung, H.; Lee, A.; Jo, S.H.; Park, H.J.; Jung, W.Y.; Kim, H.-S.; Lee, H.-J.; Jeong, S.-G.; Kim, Y.-S.; Cho, H.S. Nitrogen signaling genes and SOC1 determine the flowering time in a reciprocal negative feedback loop in Chinese cabbage (Brassica rapa L.) based on CRISPR/Cas9-mediated mutagenesis of multiple BrSOC1 homologs. Int. J. Mol. Sci. 2021, 22, 4631. [CrossRef] [PubMed]

35. Martin, M. Cutadapt removes adapter sequences from high-throughput sequencing reads. EMBnet J. 2011, 17, 10-12. [CrossRef]

36. Cox, M.P.; Peterson, D.A.; Biggs, P.J. SolexaQA: At-a-glance quality assessment of Illumina second-generation sequencing data. BMC Bioinform. 2010, 11, 485. [CrossRef]

37. Li, H.; Durbin, R. Fast and accurate short read alignment with Burrows-Wheeler transform. Bioinformatics 2009, 25, 1754-1760. [CrossRef] [PubMed]

38. Li, H.; Handsaker, B.; Wysoker, A.; Fennell, T.; Ruan, J.; Homer, N.; Marth, G.; Abecasis, G.; Durbin, R.; 1000 Genome Project Data Processing Subgroup. The Sequence Alignment/Map format and SAMtools. Bioinformatics 2009, 25, 2078-2079. [CrossRef] [PubMed] 
39. Kim, J.E.; Oh, S.K.; Lee, J.H.; Lee, B.M.; Jo, S.H. Genome-wide SNP calling using next generation sequencing data in tomato. Mol. Cells 2014, 37, 36-42. [CrossRef]

40. Bae, S.; Park, J.; Kim, J.S. Cas-OFFinder: A fast and versatile algorithm that searches for potential off-target sites of Cas9 RNA-guided endonucleases. Bioinformatics 2014, 30, 1473-1475. [CrossRef]

41. Dai, Y.; Zhang, S.; Sun, X.; Li, G.; Yuan, L.; Li, F.; Zhang, H.; Zhang, S.; Chen, G.; Wang, C.; et al. Comparative transcriptome analysis of gene expression and regulatory characteristics associated with different vernalization periods in Brassica rapa. Genes 2020, 11, 392. [CrossRef]

42. Song, H.; Yi, H.; Do, C.; Han, C.-T.; Nou, I.-S.; Hur, Y. Genome-wide analysis of gene expression to distinguish photoperioddependent and -independent flowering in Brassicaceae. Genes Genom. 2017, 39, 207-223. [CrossRef]

43. Lin, S.I.; Wang, J.G.; Poon, S.Y.; Su, C.L.; Wang, S.S.; Chiou, T.J. Differential regulation of FLOWERING LOCUS C expression by vernalization in cabbage and Arabidopsis. Plant Physiol. 2005, 137, 1037-1048. [CrossRef] [PubMed]

44. King, G.J.; Chanson, A.H.; McCallum, E.J.; Ohme-Takagi, M.; Byriel, K.; Hill, J.M.; Martin, J.L.; Mylne, J.S. The Arabidopsis B3 domain protein VERNALIZATION1 (VRN1) is involved in processes essential for development, with structural and mutational studies revealing its DNA-binding surface. J. Biol. Chem. 2013, 288, 3198-3207. [CrossRef] [PubMed]

45. Cai, Y.; Chen, L.; Liu, X.; Guo, C.; Sun, S.; Wu, C.; Jiang, B.; Han, T.; Hou, W. CRISPR/Cas9-mediated targeted mutagenesis of GmFT2a delays flowering time in soya bean. Plant Biotechnol. J. 2018, 16, 176-185. [CrossRef]

46. Jing, C.; Wei, M.; Fang, P.; Song, R.; Qi, W. Pollen-specific CRISPR/Cas9 system to increase heritable gene mutations in maize. Agriculture 2021, 11, 751. [CrossRef]

47. Zhang, H.; Zhang, J.; Wei, P.; Zhang, B.; Gou, F.; Feng, Z.; Mao, Y.; Yang, L.; Zhang, H.; Xu, N.; et al. The CRISPR/Cas9 system produces specific and homozygous targeted gene editing in rice in one generation. Plant Biotechnol. J. 2014, 12, 797-807. [CrossRef]

48. Ma, X.; Zhang, Q.; Zhu, Q.; Liu, W.; Chen, Y.; Qiu, R.; Wang, B.; Yang, Z.; Li, H.; Lin, Y.; et al. A robust CRISPR/Cas9 system for convenient, high-efficiency multiplex genome editing in monocot and dicot plants. Mol. Plant 2015, 8, 1274-1284. [CrossRef]

49. Gao, X.; Chen, J.; Dai, X.; Zhang, D.; Zhao, Y. An effective strategy for reliably isolating heritable and Cas9-free Arabidopsis mutants generated by CRISPR/Cas9-mediated genome editing. Plant Physiol. 2016, 171, 1794-1800. [CrossRef]

50. Pyott, D.E.; Sheehan, E.; Molnar, A. Engineering of CRISPR/Cas9-mediated potyvirus resistance in transgene-free Arabidopsis plants. Mol. Plant Pathol. 2016, 17, 1276-1288. [CrossRef]

51. Li, M.; Li, X.; Zhou, Z.; Wu, P.; Fang, M.; Pan, X.; Lin, Q.; Luo, W.; Wu, G.; Li, H. Reassessment of the Four Yield-related Genes Gn1a, DEP1, GS3, and IPA1 in Rice Using a CRISPR/Cas9 System. Front. Plant Sci. 2016, 7, 377. [CrossRef] [PubMed]

52. Zhou, H.; He, M.; Li, J.; Chen, L.; Huang, Z.; Zheng, S.; Zhu, L.; Ni, E.; Jiang, D.; Zhao, B.; et al. Development of commercial thermo-sensitive genic male sterile rice accelerates hybrid rice breeding using the CRISPR/Cas9-mediated TMS5 editing system. Sci. Rep. 2016, 6, 37395. [CrossRef] [PubMed]

53. Zhang, Y.; Liang, Z.; Zong, Y.; Wang, Y.; Liu, J.; Chen, K.; Qiu, J.-L.; Gao, C. Efficient and transgene-free genome editing in wheat through transient expression of CRISPR/Cas9 DNA or RNA. Nat. Commun. 2016, 7, 12617. [CrossRef] [PubMed]

54. Soyk, S.; Muller, N.A.; Park, S.J.; Schmalenbach, I.; Jiang, K.; Hayama, R.; Zhang, L.; Van Eck, J.; Jimenez-Gomez, J.M.; Lippman, Z.B. Variation in the flowering gene SELF PRUNING 5G promotes day-neutrality and early yield in tomato. Nat. Genet. 2017, 49, 162-168. [CrossRef] [PubMed] 